\title{
Prospective memory skill
}

\author{
STEPHEN J. ANDRZEJEWSKI \\ Hamilton College, Clinton, New York
}

and

\author{
CATHLEEN M. MOORE, MARIA CORVETTE, and DOUGLAS HERRMANN \\ Laboratory of Socio-Environmental Studies, National Institute of Mental Health, Bethesda, Maryland
}

\begin{abstract}
Two experiments examined the likelihood of remembering each of 24 different kinds of appointments (which differed from one another in importance, retention interval, amount of recurrence, and precision with which the appointment is to be met) as a function of their frequency of occurrence. In Experiment 1, subjects rated how often they experienced and forgot to meet the different kinds of appointments. In Experiment 2, subjects kept a diary over a 3-week period of their appointments and which ones they forgot to meet. In both experiments, we found a strong positive correlation, across the different kinds of appointments, between the likelihood of remembering to meet a certain kind of appointment and the frequency of having such appointments.
\end{abstract}

Although research has clearly demonstrated a relationship between memory skills and task experience, it has done so only for retrospective memory tasks (i.e., tasks that involve remembering events or previously learned information; see Chase \& Ericsson, 1982; Herrmann, Buschke, \& Gall, 1987). No research has examined whether the prospective remembering of obligations and appointments (Meacham, 1988; Winograd, 1988) might also be related to task experience.

In the present study, we investigated the relationship between prospective memory performance for remembering appointments and the frequency of experience with appointments in everyday life. In the first experiment, subjects rated how often they experienced and how often they remembered to meet different kinds of appointments. In the second experiment, subjects reported, rather than rated, the same information for appointments in a diary that was kept for 3 weeks. Metacognitive reports, while generally only moderately valid, nevertheless provide some indication of a person's actual memory performance (Herrmann, 1990). Thus, if prospective remembering has a skill element to it, reported success at remembering to meet appointments should be directly correlated with reported frequency of appointment occurrence. It will be seen that both experiments revealed a strong positive relationship between the likelihood of remembering to meet a certain kind of appointment and the frequency of having such appointments.

\footnotetext{
The authors thank Virginia Marbley for her generous assistance. Requests for reprints of this article and/or the appointments questionnaire should be sent to Douglas Herrmann, Director, Collection Procedures Research Laboratory, Bureau of Labor Statistics, 441 G. St. N.W., Washington, DC 20212.
}

\section{EXPERIMENT 1}

\section{Method}

Subjects. Forty-five undergraduates from Hamilton College participated in Experiment 1. Each subject was paid $\$ 2$ to participate in the experiment.

Materials and Procedures. A 24-question survey asked subjects about how frequently they experienced and how often they succeeded at meeting certain kinds of appointments. Each question asked about one of four possible combinations of attributes of an appointment. These attributes included the following: importance (important and unimportant), type (recurring and unique), duration (brief, 1-2 days; moderate, approximately 1 week; and extended, approximately 1 month or greater), and punctuality (precisely timed and intervally timed).

The subjects were directed to report two types of information about each kind of appointment. First, they were asked to report how often they had to make each kind of appointment on a 7-point scale, ranging from the kind of appointment that the subject never had (1) to the kind of appointment that the subject experienced "almost always" (7) (defined as nearly every day). Second, they were asked to estimate the percentage of appointments of a particular kind that they failed to meet because they had forgotten the appointment. The subjects were told that their estimates were not to include failures to meet appointments that had occurred for other reasons, such as failure to find transportation or cancellation of the appointment by the other party (Levy \& Loftus, 1984).

\section{Results and Discussion}

The percentages of estimated appointment forgetting were transformed to represent percentages of estimated appointment remembering in order to facilitate discussion of the results. Table 1 provides the mean ratings of frequency of appointment occurrence and proportion of remembering for each of the 24 appointment types. Inspection of the table reveals that both the reported frequency and the proportion of remembering was highest for important appointments and that the patterns of the data were roughly comparable across the two measures. Additionally, the correlation of the mean frequency of appointments and mean proportion of appointments remem- 
Table 1

Mean Number of Appointments and Percentage of Appointments Typically Remembered

\begin{tabular}{|c|c|c|c|c|}
\hline & \multicolumn{2}{|c|}{ Unique } & \multicolumn{2}{|c|}{ Recurring } \\
\hline & Precise & Interval & Precise & Interval \\
\hline \multicolumn{5}{|c|}{ Important } \\
\hline \multicolumn{5}{|c|}{ Brief } \\
\hline$M$ & 4.2 & 3.7 & 4.9 & 4.0 \\
\hline$\%$ & 98.6 & 97.63 & 96.87 & 94.49 \\
\hline \multicolumn{5}{|c|}{ Moderate } \\
\hline$M$ & 3.8 & 3.3 & 4.4 & 3.8 \\
\hline$\%$ & 97.12 & 96.27 & 95.29 & 94.54 \\
\hline \multicolumn{5}{|c|}{ Extended } \\
\hline$M$ & 3.0 & 3.0 & 3.2 & 3.0 \\
\hline$\%$ & 96.27 & 93.67 & 91.80 & 93.36 \\
\hline \multicolumn{5}{|c|}{ Unimportant } \\
\hline \multicolumn{5}{|c|}{ Brief } \\
\hline$M$ & 3.6 & 3.3 & 3.3 & 3.0 \\
\hline$\%$ & 93.92 & 93.58 & 88.76 & 90.03 \\
\hline \multicolumn{5}{|c|}{ Moderate } \\
\hline$M$ & 3.4 & 3.1 & 3.2 & 3.4 \\
\hline$\%$ & 90.27 & 91.96 & 87.74 & 90.67 \\
\hline \multicolumn{5}{|c|}{ Extended } \\
\hline $\boldsymbol{M}$ & 2.8 & 2.7 & 2.5 & 2.6 \\
\hline$\%$ & 85.98 & 84.76 & 85.92 & 86.43 \\
\hline
\end{tabular}

Note $-M=$ mean number of appointments; $\%=$ percentage of appointments typically remembered.

bered, across all appointments, was substantial $[r(22)=$ $.78, p<.01]$.

However, since self-reports sometimes do not validly reflect performance (Herrmann, 1990), we investigated the remembering of appointments with a more valid measure than self-reports (i.e., a diary study of memory for appointments) in Experiment 2. If the self-reports used in Experiment 1 provided a valid indication of the relationship between remembering and frequency of appointments, then the diary reports in Experiment 2 should reveal that the likelihood of remembering appointments is positively related to their frequency.

\section{EXPERIMENT 2}

\section{Method}

Subjects. Twenty-seven undergraduates from Hamilton College participated in Experiment 2. Each subject was paid $\$ 3$ for an initial session and $\$ 9$ for keeping a diary concerning appointments for a 3-week period.

Materials and Procedure. The subjects were instructed that they were to maintain a diary checklist concerning their success at remembering appointments for a 3-week period. The checklist required the subject to record the occurrence of an appointment, a description of the appointment, and some of its attributes (defined in the same way as in Experiment 1): how important the appointment was, how long ago it was made (duration), the appointment's uniqueness, and the punctuality with which it was to be met.

The subjects were told not to record any appointments on the checklist until after they met or forgot to meet them; this direction was given so that the checklist would not serve as a reminder. Additionally, the subjects were told not to report appointments missed for other reasons, such as rescheduling or intentional failures to meet (Levy \& Loftus, 1984). To ensure that the subjects were attentive to their diaries, they were required to turn them in twice a week for 3 weeks. They were asked not to discuss the nature of their training with other participants in the experiment during the diary period; they indicated later that they had complied with this request.
The diary records of each subject were coded according to the levels of the four appointment attributes used in Experiment 1: importance (important, unimportant), duration (brief, moderate, extended), uniqueness (unique, recurring), and punctuality (precise, within an interval). The frequency of experience of each of the 24 kinds of appointments was then counted and the percentage of remembering was computed for each subject for the 24 kinds of appointments.

\section{Results and Discussion}

The mean frequency per appointment, the number of subjects who had each kind of appointment, and the percentage of appointments missed are presented in Table 2. As in Experiment 1, important appointments were more common than were unimportant appointments. The correlation between mean frequencies and percentage of remembering, presented in Table 2 for the appointments reported by 1 or more subjects, was $r=.72, t(22)=4.891$, $p<.01$. Since Table 2 is a composite of responses of the subjects who contributed in different amounts to different cells of the table, the correlation between frequency and performance was calculated for each subject. The mean correlation for these subjects, like that for the overall table, was substantial $[\rho=.89, t(26)=7.45, p<.01$, ranging from $\rho=.73$ to $\rho=.95]$.

Finally, it should be noted that the pattern of results in Experiment 2 agreed well with that found in Experiment 1 . The reported frequency of the different kinds of

Table 2

Mean Number of Appointments, Number of Subjects Reporting the Kind of Appointment, and Percentage of Appointments Remembered During a Diary Study

\begin{tabular}{|c|c|c|c|c|}
\hline & \multicolumn{2}{|c|}{ Unique } & \multicolumn{2}{|c|}{ Recurring } \\
\hline & Precise & Interval & Precise & Interval \\
\hline \multicolumn{5}{|c|}{ Important } \\
\hline \multicolumn{5}{|l|}{ Brief } \\
\hline$M$ & 4.2 & 2.3 & 5.9 & 1.9 \\
\hline$N$ & 26 & 23 & 17 & 14 \\
\hline$\%$ & 93.7 & 90.7 & 98.0 & 84.6 \\
\hline \multicolumn{5}{|c|}{ Moderate } \\
\hline$M$ & 3.9 & 0.5 & 2.5 & 1.6 \\
\hline$N$ & 22 & 7 & 15 & 5 \\
\hline$\%$ & 96.6 & 91.6 & 97.4 & 75.0 \\
\hline \multicolumn{5}{|c|}{ Extended } \\
\hline$M$ & 1.4 & 3.0 & 3.7 & 1.0 \\
\hline$N$ & 7 & 1 & 4 & 2 \\
\hline$\%$ & 100.0 & 100.0 & 93.3 & $: 00.0$ \\
\hline \multicolumn{5}{|c|}{ Unimportant } \\
\hline \multicolumn{5}{|l|}{ Brief } \\
\hline $\boldsymbol{M}$ & 1.6 & 1.5 & 1.0 & 1.4 \\
\hline$N$ & 9 & 10 & 3 & 7 \\
\hline$\%$ & 80.0 & 100.0 & 66.6 & 90.0 \\
\hline \multicolumn{5}{|c|}{ Moderate } \\
\hline$M$ & 1.0 & 1.0 & - & 1.0 \\
\hline$N$ & 3 & 2 & 0 & 1 \\
\hline$\%$ & 33.3 & 100.0 & - & 100.0 \\
\hline \multicolumn{5}{|c|}{ Extended } \\
\hline$M$ & 1.0 & - & - & - \\
\hline$N$ & 1 & 0 & 0 & 0 \\
\hline$\%$ & 100.0 & - & - & - \\
\hline
\end{tabular}

Note $-M=$ mean number of appointments; $N=$ number of subjects reporting the kind of appointment; $\%=$ percentage of appointments remembered. 
appointments in Experiment 2 was highly correlated with the estimated mean frequency per appointment reported by the subjects in Experiment $1(\rho=.82, p<.01$, based on those kinds of appointments reported by $10 \%$ or more of the diary subjects). Similarly, the proportions of remembering of the different kinds of appointments in Experiment 2 were significantly correlated with the estimated remembering rates reported by the subjects in Experiment $1(\rho=.51, p<.05)$

To further assess the robustness of the relationship between task frequency and prospective memory skill, we examined the literature for other studies that supported such development. All of the studies we found supported the hypothesis that prospective memory performance covaries with task practice. First, subjects returned postcards at designated times better when they had to do so eight times than when they had to do so four times $[t(7)=2.33, p<.05$, one-tailed test; Meacham \& Leiman, 1982]. Second, the frequency of prospective tasks to be carried out and the proportion of those tasks that actually were carried out were $\rho=.71, p<.01$ (Meacham $\&$ Kushner, 1980, Table 2 of their report). Third, a correlation between the proportion of successful performance and task frequency was substantial and over both retrospective and prospective memory tasks $(r=.74, p<.01$; Shlechter, Herrmann, \& Toglia, 1990). Fourth, subjects' estimates of frequency of aid use and aid dependability, as averaged over different kinds of aids, were correlated (Spearman $\rho=.4$; Intons-Peterson \& Fournier, 1986).

Thus, Experiments 1 and 2 and prior research show that the degree of experience with prospective memory tasks covaries with the success at such tasks. Apparently, experience at a particular kind of prospective memory task either prepares a person to perform this task better in the future or inclines a person to seek out tasks that he or she performs successfully. It remains for experimental work to determine which of these two explanations account for this substantial correlation.

\section{REFERENCES}

Chase, W. G., \& Ericsson, K. A. (1982). Skill and working memory. Psychology of Learning \& Motivation, 16, 2-58.

HerrmanN, D. J. (1990). Self-perceptions of memory performance. In W. Schaie, C. Schooler, \& J. Rodin (Eds.), Self-directedness and efficacy: Causes and effects throughout the life course (pp. 199-211). Hillsdale, NJ: Erlbaum.

Herrmann, D. J., Buschke, H., \& Gall, M. (1987). Improving retrieval. Applied Cognitive Psychology, 9, 27-33.

Intons-Peterson, M. J., \& Fournier, J. (1986). External and internal memory aids: When and how to use them. Journal of Experimental Psychology: General, 115, 267-280.

Levy, R. L., \& LofTus, G. R. (1984). Compliance and memory. In J. E. Harris \& P. E. Morris (Eds.), Everyday memory, actions, and absentmindedness (pp. 93-112). London: Academic Press.

MEACHAM, J. A. (1988). Interpersonal relations and prospective remembering. In M. Gruneberg, P. Morris, \& R. Sykes (Eds.), Practical aspects of memory: Current research and issues (Vol. 1; pp. 354-359). Chichester, U.K.: Wiley.

MeACham, J. A., \& KuShNER, S. (1980). Anxiety, prospective remembering, and performance of planned action. Journal of General Psychology, 103, 203-209.

Meacham, J. A., \& Leiman, B. (1982). Remembering to perform future actions. In U. Neisser (Ed.), Memory observed: Remembering in natural context (pp. 327-336). San Francisco: W. H. Freeman.

Shlechter, T. M., HerrmanN, D. J., \& Toglia, M. P. (1990). An investigation of people's metamemories for naturally occurring events. Applied Cognitive Psychology, 4, 213-217.

WINOGRAD, E. (1988). Some observations on prospective remembering. In M. Gruneberg, P. Morris, \& R. Sykes (Eds.), Practical aspects of memory: Current research and issues (Vol. 1; pp. 348-359). Chichester, U.K.: Wiley.

(Manuscript received December 27, 1990.) 